\title{
Implications of oxidative stress in chronic kidney disease: a review on current concepts and therapies
}

\author{
Sagar Verma ${ }^{1}$, Priyanka Singh ${ }^{2}$, Shiffali Khurana ${ }^{1}$, Nirmal Kumar Ganguly ${ }^{1}$, Ritushree Kukreti ${ }^{2}$, Luciano Saso ${ }^{3}$, \\ Devinder Singh Rana ${ }^{4}$, Vibha Taneja ${ }^{1}$, Vinant Bhargava ${ }^{4}$ \\ ${ }^{1}$ Department of Research, Sir Ganga Ram Hospital, New Delhi, India \\ ${ }^{2}$ CSIR-Institute of Genomics and Integrative Biology, New Delhi, India \\ ${ }^{3}$ Department of Physiology and Pharmacology, Sapienza University of Rome, Rome, Italy \\ ${ }^{4}$ Department of Nephrology, Sir Ganga Ram Hospital, New Delhi, India
}

\begin{abstract}
Moderate levels of endogenous reactive oxygen species (ROS) are important for various cellular activities, but high levels lead to toxicity and are associated with various diseases. Levels of ROS are maintained as a balance between oxidants and antioxidants. Accumulating data suggest that oxidative stress is a major factor in deterioration of renal function. In this review, we highlight the possible mechanism by which oxidative stress can lead to chronic kidney disease (CKD). This review also describes therapies that counter the effect of oxidative stress in CKD patients. Numerous factors such as upregulation of genes involved in oxidative phosphorylation and ROS generation, chronic inflammation, vitamin D deficiency, and a compromised antioxidant defense mechanism system cause progressive detrimental effects on renal function that eventually lead to loss of kidney function. Patients with renal dysfunction are highly susceptible to oxidative stress, as risk factors such as diabetes, renal hypertension, dietary restrictions, hemodialysis, and old age predispose them to increased levels of ROS. Biomolecular adducts (DNA, proteins, and lipids) formed due to reaction with ROS can be used to determine oxidative stress levels. Based on the strong correlation between oxidative stress and CKD, reversal of oxidative stress is being explored as a major therapeutic option. Xanthine oxidase inhibitors, dietary antioxidants, and other agents that scavenge free radicals are gaining interest as treatment modalities in CKD patients.
\end{abstract}

Keywords: Antioxidants, Chronic kidney disease, Oxidative stress, Renal dialysis

\section{Background}

Living organisms require oxygen to sustain their existence, and oxidative compounds such as reactive oxygen species (ROS) and reactive nitrogen species in cells are produced from molecular oxygen as a consequence of aerobic metabo-

Received: August 29, 2020; Revised: February 5, 2021; Accepted: February 5, 2021

Editor: Tae-Hyun Yoo, Yonsei University, Seoul, Republic of Korea

Correspondence: Vinant Bhargava

Department of Nephrology, Sir Ganga Ram Hospital, Sir Ganga Ram Hospital, Rajinder Nagar, New Delhi-110060, India. E-mail: vinant.bhargava@ gmail.com

ORCID: https://orcid.org/0000-0002-3360-4666

Vibha Taneja

Department of Research, Sir Ganga Ram Hospital, Sir Ganga Ram Hospital, Rajinder Nagar, New Delhi-110060, India. E-mail: vibha.taneja@sgrh.com ORCID: https://orcid.org/0000-0001-5457-9992

Copyright (C) 2021 by The Korean Society of Nephrology

(a) This is an Open Access article distributed under the terms of the Creative Commons Attribution Non-Commercial and No Derivatives License (http:// creativecommons.org/licenses/by-nc-nd/4.0/) which permits unrestricted non-commercial use, distribution of the material without any modifications, and reproduction in any medium, provided the original works properly cited. 
lism. ROS can be classified as either free radicals or non-radicals; free radicals include superoxide anion radical $\left(\mathrm{O}_{2}^{-}\right)$, peroxyl (ROO•), alkoxyl (RO•), nitric oxide (NO•), and hydroxyl radical $(\mathrm{OH} \bullet)$. Non-radical species include peroxynitrite $\left(\mathrm{ONOO}^{-}\right)$, hydrogen peroxide $\left(\mathrm{H}_{2} \mathrm{O}_{2}\right)$, and hypochlorous acid (HOCl) [1]. ROS exhibit both beneficial and harmful effects on the cell. Oxidative compounds aid in physiological cell processes when produced in low to moderate concentration, but higher concentration causes detrimental effects including damage to molecular components such as DNA, proteins, and lipids; production of pro-and anti-inflammatory cytokines; and activation of several stress-induced transcription factors [2]. Endogenous sources of ROS include several cellular enzymes such as nicotinamide adenine dinucleotide phosphate (NADPH) oxidase (Nox), xanthine oxidase (XO), mitochondrial oxidases, cyclooxygenase, myeloperoxidase, amino acid oxidase, lipoxygenase, and peroxisomes. Exogenous sources of oxidants include cigarette smoke, ozone exposure, hyperoxia, ionizing radiation, and heavy metal ions.

To counterbalance the effects of oxidants, the human body is equipped with enzymatic and nonenzymatic antioxidant defense mechanisms. Antioxidant enzyme defenses include superoxide dismutase (SOD), catalase, glutathione peroxidase, thioredoxin and peroxiredoxin, and glutathione transferase. Nonenzymatic antioxidants include vitamin C, vitamin $\mathrm{E}$, glutathione, and carotenoids.

When the balance between oxidants and antioxidants shifts in favor of oxidants, oxidative stress is produced. Oxidative stress is known to trigger several pathological conditions including neurological disorders [3], cardiovascular diseases (CVDs) [4], diabetes [5], cancer, and asthma [6] and has been associated with kidney dysfunction [7]. In pyelonephritis, renal dysfunction is caused by ROS-mediated lipid peroxidation and DNA damage, leading to structural and functional aberrations in the kidney [8]. Administration of free radical scavengers such as catalase and dimethyl-sulfoxide neutralizes ROS production, resulting in reversal of oxidative damage and histopathological changes in a chronic pyelonephritis mouse model [9]. Over the last few decades, a large number of clinical, experimental, and theoretical investigations have been conducted for detection of signs of oxidative stress in renal failure patients [10-12]. Oxidative stress is widely considered a biochemical hallmark of chronic kidney disease (CKD) influencing progression of renal function deterioration [13] and onset of major systemic comorbidities including CVD.

\section{Understanding the pathogenesis and mediators of oxidative stress in CKD}

Kidneys are responsible for homeostasis of extracellular fluids. Progressive decline in kidney function causes CKD, which leads to accumulation of toxic waste (uremia). CKD has become a global health concern, with more than one million annual deaths from end-stage renal disease (ESRD) [14]. CKD is diagnosed by either a reduction in glomerular filtration rate (GFR) and/or the presence of albumin, red blood cells, or white blood cells in the urine. The normal GFR in a healthy individual is $\geq 90 \mathrm{~mL} / \mathrm{min} / 1.73 \mathrm{~m}^{2}$, whereas GFR $<60 \mathrm{~mL} / \mathrm{min} / 1.73 \mathrm{~m}^{2}$ for three months or more is indicative of decreased kidney function or presence of CKD [15]. Onset and progression of CKD are associated with various components of metabolic syndrome (MetS) including hypertension, diabetes, obesity, and dyslipidemia. The relationship between MetS and CKD is complex and bidirectional. However, it is difficult to define the etiological role of MetS in CKD as the individual components of MetS are sensitive to lifestyle modifications, medications, and other factors. Some of the additional risk factors for CKD include exposure to nephrotoxins, acute kidney disease, smoking, and aging [16]. All these risk factors significantly disturb the redox balance in the body. Increased oxidative species and decreased antioxidant capacity have been documented in various renal insufficiencies including CKD (Fig. 1).

In kidney diseases, cellular oxidative stress induces apoptosis and senescence, reduced regenerative capability of cells, and fibrosis in the kidney cells. Oxidative stress leads to accumulation of extracellular matrix proteins, podocyte damage, mesangial expansion, renal hypertrophy, endothelial dysfunction, tubulointerstitial fibrosis, and glomerulosclerosis [1]. Thus, oxidative stress further contributes to deterioration of renal function and disease progression.

The mitochondrial electron transport complex is major source of ROS production via oxidative phosphorylation system (OXPHOS) in the cell. In CKD patients, mitochondrial deregulation causes overproduction of ROS and enhances oxidative stress. Several genes involved in OXPHOS have been found to be upregulated in CKD patients [17]. Other enzymes including Nox, XO, and lipoxygenases, which initiate ROS production, are upregulated in CKD [18]. Several isoforms 


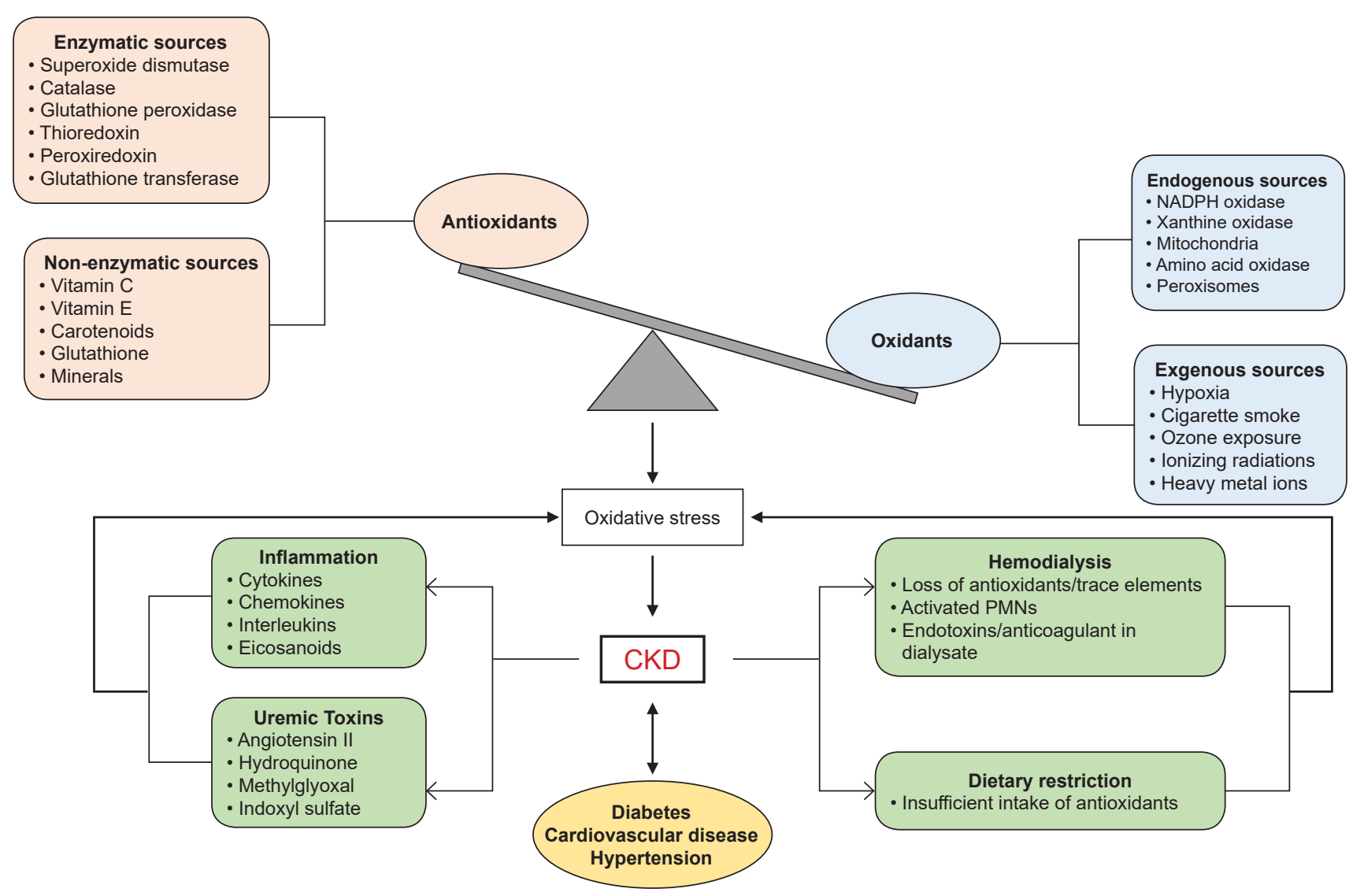

Figure 1. Factors influencing oxidative stress in chronic kidney disease (CKD). Disturbance in the balance of antioxidants (pink box) and oxidants (light blue box) causes oxidative stress to can lead to CKD. Additional factors that contribute to CKD by enhancing oxidative stress are shown in the green box. Comorbid conditions associated with CKD are listed in orange.

$\mathrm{NADPH}$, nicotinamide adenine dinucleotide phosphate; PMN, polymorphonuclear neutrophil.

of Nox have been implicated in renal diseases including nephrolithiasis, hypertension, membranous nephropathy, renal transplantation, and acute kidney injury [19]. Nox4, the predominant Nox isoform in kidney, acts as a major source of ROS and plays a central role in chronic renal diseases such as diabetic nephropathy [20]. Increased Nox-dependent superoxide generation has been reported in patients at an early stage of chronic renal failure [21] and has been shown to contribute to microvascular dysfunction in $\mathrm{CKD}$ [22].

$\mathrm{XO}$ is the oxidative radical-producing isoform of xanthine oxidoreductase (XOR), also known as urate-producing enzyme. The XO enzyme catalyzes oxidation of hypoxanthine to xanthine and then xanthine to uric acid together with ROS release. XO activity is higher in plasma of CKD patients and has been suggested to be an independent predictor of cardiovascular events in CKD patients [23]. Recently, Terawaki et al. [24] reported relationships between estimated GFR
(eGFR) and both XO and XOR activity. Further, these researchers showed higher XOR redox, the ratio of XO to total $\mathrm{XOR}$, in the plasma of advanced CKD patients, indicating its role in elevated ROS production.

Nitric oxide (NO) influences kidney function and aids in maintaining normal blood pressure by promoting natriuresis and diuresis, aiding in adaptation to variations in dietary salt intake. NO also acts as a powerful anti-oxidative agent that minimizes the adverse effects of $\mathrm{O}_{2}^{-}$. Studies have reported reduced NO production in CKD patients [25]. Multiple factors are responsible for the diminished levels of NO including decreased availability of L-arginine, the substrate for NO synthesis, and increased levels of NO synthase inhibitors such as asymmetric dimethylarginine [26]. The decreased NO activity and further deactivation by superoxide anion radical increase vascular resistance in renal arteries and manifest as hypertensive nephropathy and CVD [27]. 
CKD patients have severe vitamin $\mathrm{D}$ deficiency that is further decreased by reduced activity of the enzyme 1- $\alpha$ hydroxylase (CYP27B1), which converts 25-hydroxyvitamin D to its more active form, 1,25-dihydroxyvitamin D. Deficiency of vitamin D causes oxidative stress, inflammation, hypertension, and hypocalcemia, which lead to progression of CKD and CVD [28].

Elevated levels of lipid-associated oxidation markers such as F2-isoprostanes and malondialdehyde (MDA); protein-associated oxidation markers including oxidized low-density lipoproteins, carbonyls, and glycations; and DNA-associated oxidation markers such as 8-oxo-2'-deoxyguanosine reflect the status of oxidative stress in CKD and can be correlated to disease severity (Fig. 2). The free radicals generated due to oxidative stress have high reactivity and short half-lives (seconds) and are difficult to quantitate in clinical settings. Therefore, biomolecular adducts having longer half-lives (hours to weeks) have become an important tool to measure the levels of oxidative stress.

Oxidative stress is an important contributor to chronic inflammation in CKD. Long-term low-grade inflammation has been implicated in the pathophysiology of CKD. Damage to the kidney causes inflammation and recruits macrophages and leucocytes to result in an "oxidative burst" that causes overproduction of ROS. Accumulation of ROS triggers an inflammatory chain reaction by recruiting macrophages and secreting cytokines, chemokines, and eicosanoids. Cytokines and inflammatory mediators such as tumor necrosis factor (TNF)- $\alpha$, transforming growth factor $\beta$, and interleukins (ILs) have been shown to modulate GFR, renal blood flow, and sodium excretion [29]. In addition, oxidative stress activates nuclear factor (NF)- $\mathrm{B}$, a transcription factor responsible for expression of inflammatory mediator genes [30]. Oxidative stress affects the phosphorylation and degradation of I- $\kappa \mathrm{B}$, an inhibitory protein that maintains NF- $\kappa$ B in an inactivated state, and leads to activation of NF- $\kappa$ B. The presence of antioxidants inhibits activation of NF- $\kappa$ B by ROS [31]. Patients with advanced-stage CKD have high levels of inflammation markers such as C-reactive protein, TNF- $\alpha$, and IL- 6 as well as oxidative stress markers such as plasma protein carbonyls and F2-isoprostanes, supporting the link between inflammation and oxidative stress in disease pathogenesis [32,33].

Antioxidant defense mechanisms have been shown to be compromised in patients with renal dysfunction. The free radical scavenger SOD is down-regulated in renal patients [34]. Genetic polymorphism in glutathione-S transferase, another antioxidant enzyme, contributes to elevated oxidative stress in ESRD patients [35]. In addition, reduced plasma levels of antioxidant enzymes including catalase, glutathione peroxidase, intracellular glutathione, and thiol have been reported in patients with CKD [36].

\section{ROS increase in renal patients}

Increased susceptibility to oxidative stress in patients with renal dysfunction can be attributed to various mechanisms (Fig. 1). Risk factors such as diabetes, renal hypertension, and old age predispose these patients to increased levels of oxidative stress compared to the normal population. Another possible reason is nutritional limitation of fresh vegetables and fruits to avoid hyperkalemia and low level/intake of vitamin C. Normal potassium level is critical to maintain normal heart function; in hyperkalemia, the reduced ability

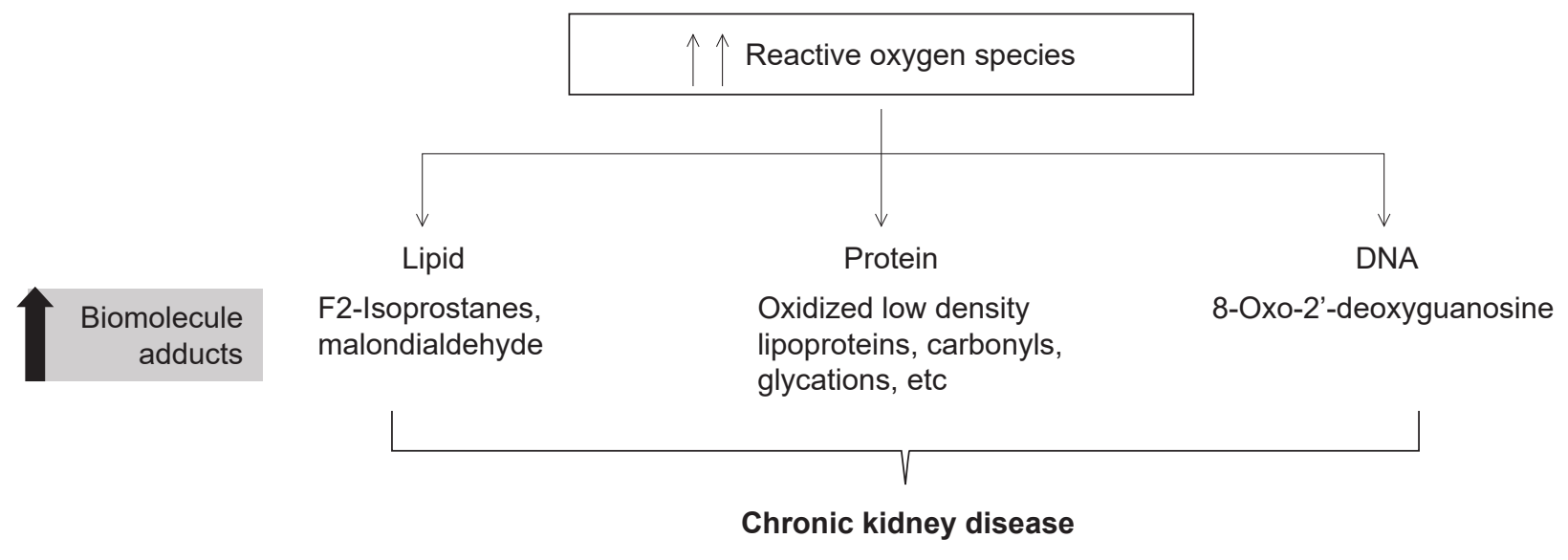

Figure 2. Elevated levels of biomolecular adducts are potential biomarkers to measure oxidative stress in chronic kidney disease. 
of the kidney to excrete potassium from blood can disrupt potassium hemostasis and lead to abnormal heart rhythms. Severe hyperkalemic condition results in mortality.

Renal dysfunction leads to accumulation of several uremic toxins such as indoxyl sulfate, $\mathrm{p}$-cresol, and p-cresyl sulfate, which trigger progression of CKD and increase the risk of CVD [37-39]. Indoxyl sulfate stimulates oxidative stress to contribute to atherosclerotic vascular disease, arrhythmia, and chronic heart failure, indicating its role in the high prevalence of CVD that accelerates progression of CKD [40]. In addition, accumulation of uremic toxins in CKD causes uremic sarcopenia and uremic osteoporosis [41,42]. Similarly, p-cresyl sulfate increases oxidative stress and is involved in various mechanisms associated with cardiovascular and renal dysfunction [43].

Hemodialysis (HD), which is currently one of the major renal replacement therapies, is associated with increased oxidative stress [44]. HD is a nonselective procedure that removes solutes and results in loss of antioxidant molecules including water-soluble vitamins [45-48] and trace elements [49]. Furthermore, the bioincompatible dialyzer membranes used in HD cause ROS production via activation of polymorphonuclear neutrophils (PMNs). Activated PMNs generate myeloperoxidase, which is a key trigger for ROS activation and inactivation of nitrogen oxide. Studies have shown that increased serum myeloperoxidase is associated with markers of both inflammation and mortality in HD patients [50]. The presence of bacterial endotoxins such as lipopolysaccharide or anticoagulants in the dialysate triggers formation of oxidative species [51-53].

\section{Therapies to counter oxidative stress in CKD}

A growing body of evidence clearly suggests a role of oxidative stress in the pathogenesis of CKD and has prompted researchers worldwide to explore the possibility of reversing oxidative stress. Oxidative stress is enhanced in patients undergoing HD. Studies indicate that supplementation of antioxidants is beneficial in treating and preventing progression of CKD in predialysis as well as dialysis patients [54]. Several clinical trials have been performed to examine the therapeutic potential of various antioxidants in slowing progression of CKD.

XO inhibitors (XOi) have been the primary choice for treatment of hyperuremia associated with various diseases including CKD. The first-generation XOi allopurinol has been shown to exert a moderate nephroprotective effect by reducing ROS generation and inflammation and improving endothelial function $[55,56]$. Recently, new randomized clinical trials with second-generation XOi (febuxostat and topiroxostat) have been initiated [57]. N-acetylcysteine (NAC), a precursor of glutathione, has also emerged as a potential molecule for slowing CKD progression to ESRD by attenuating systemic oxidative stress [58]. NAC has been shown to improve endothelial dysfunction in CKD patients on HD [59].

Noxs are a major source of ROS in the kidney; therefore, Nox inhibitors are emerging as potential therapeutics for CKD [60]. Preclinical studies have shown that GKT137831 (setanaxib), a dual inhibitor of Noxl and Nox4, exhibits renoprotective effects by attenuating glomerular structural changes, podocyte loss, extracellular matrix accumulation, and albuminuria in a mouse model of diabetic nephropathy $[61,62]$. Owing to the crucial role of setanaxib in attenuating renal pathology, it has now been enrolled in a Phase 2 clinical trial for type I diabetes and kidney disease. Recently, Cha et al. [63] showed that APX-115, a novel pan-Nox inhibitor, provides better protection than setanaxib. APX-115 decreased oxidative stress and improved insulin resistance in diabetic $d b / d b$ mice. Moreover, APX-115 decreased albuminuria and preserved creatinine level [63]. Another study showed that APX-115 effectively prevented kidney injury such as oxidative stress, inflammation, and fibrosis in diabetic mice [64]. Moreover, APX-115 treatment effectively inhibited mitochondrial and peroxisomal dysfunction, suggesting pan-Nox inhibition as an effective therapy.

Nuclear factor erythroid 2-related factor 2 (Nrf2) is another emerging treatment target to counteract oxidative stress and inflammation in CKD [65]. Nrf2 is a transcription factor responsible for regulation of various antioxidant genes. Enhancing Nrf2 activity in renal tubules decreases oxidative stress and prevents kidney disease progression [66]. Bardoxolone methyl (BARD), a semisynthetic triterpenoid, is one of the most potent activators of Nrf2. BARD has been shown to increase estimated GFR and preserve kidney function in stage 4 CKD patients. This strongly suggests that restoring Nrf2 activity could potentially retard CKD progression [67].

The protective effect of dietary antioxidant micronutrients in various diseases associated with oxidative stress has been well documented. Antioxidant therapy reduces serum creatinine level and improves kidney function which contributes 
to reduced risk of progression to ESRD. Vitamins E and C are strong and powerful antioxidants that have been considered for CKD therapy [68-70].

Alpha-tocopherol, the biologically active form of vitamin E, counteracts oxidative stress by protecting against peroxidation of lipids and increasing low-density lipoprotein resistance [71]. Vitamin $\mathrm{E}$ is a strong scavenger of peroxyl radical and also regulates the expression of inflammatory genes. Supplementation with vitamin E in HD patients causes significant decrease in serum MDA and induces SOD1 and catalase activity [68]. In addition, vitamin E-modified cellulose membrane use in HD has been shown to suppress oxidative stress and inflammation and improves endothelial function. Furthermore, hemolipodialysis has been shown to reduce oxidative stress caused during HD using vitamin $\mathrm{C}$ and liposomes containing vitamin $\mathrm{E}$ in the dialysate [72]. However, daily administration of vitamin $\mathrm{E}$ in ESRD patients significantly reduces cardiovascular complications but does not affect mortality [73]. Reduced vitamin C level has been observed in CKD patients undergoing HD. Vitamin C prevents oxidative damage by directly scavenging superoxide anion and hydroxyl radical. A moderate dose of vitamin $\mathrm{C}$ has been suggested as a corrective measure in CKD. Coadministration of vitamin $\mathrm{C}$ and vitamin $\mathrm{E}$ decreases the formation of carbonyl compounds and MDA concentration and increases total antioxidant capacity levels in peritoneal dialysis patients [74]. CKD patients are also supplemented with 1 , 25 -vitamin $\mathrm{D}$, the active form of vitamin $\mathrm{D}$, as these patients have very a high rate of vitamin D deficiency [28]. Numerous studies have reported a beneficial effect of vitamin D supplementation, including reduced proteinuria, improvement in endothelial cardiovascular markers, increased serum level of 1, 25-vitamin D, and decreased inflammation markers and serum parathyroid hormone levels in $\mathrm{CKD}$ and dialysis patients [75-79]. A recent meta-analysis demonstrated that vitamin D supplementation modulates various parameters of oxidative stress including total antioxidant capacity, glutathione, and MDA [80]. Experimental evidence suggests that vitamin D supplementation reduces oxidative stress and inflammation by increasing Nrf2 and up-regulating antioxidant enzymes [81].

Along with lifestyle changes such as exercise, smoking cessation, and dietary measures, treatment of CKD is focused on controlling albuminuria, blood pressure, blood glucose, and lipids. Agents such as beta blockers, angiotensin-converting enzyme (ACE) inhibitors, angiotensin II receptor blockers
(ARBs), and direct renin inhibitors (DRI) suppress the renin-angiotensin-aldosterone-system (RAAS), a regulator of blood pressure. These agents have been demonstrated to attenuate oxidative stress and therefore play a protective role in early as well as end stages of kidney disease [82,83]. A meta-analysis of randomized trials showed that ACE inhibitors were effective in decreasing blood pressure and excretion of urinary protein and in slowing progression of renal disease [84]. Monotherapy with ARBs or ACE inhibitors has been shown to reduce proteinuria. Similarly, a combination of ACE inhibitors and ARBs maximizes RAAS inhibition and normalizes proteinuria and GFR. Based on experimental evidence, a combination of RAAS inhibitors was suggested to be more effective than monotherapy in attenuating the progression of renal dysfunction. However, this regimen was linked with higher occurrence of adverse events such as hypotension and hyperkalemia [85]. The effect of triple RAAS blockade therapy through administration of aldosterone antagonists in combination with ACE inhibitors and/or ARBs for treatment of patients with kidney disease is undetermined [86]. Aliskiren, the first orally bioactive DRI, has been predicted to have greater potential for suppression of RAAS than any other class of drug. Additionally, aliskiren attenuates oxidative stress and provides protection of renal tubules in patients with CKD $[83,87]$.

Natural compounds that target mitochondria, alone or in combination with conventional therapies and lifestyle modifications, are gaining worldwide interest as treatment modalities in CKD patients undergoing both conservative and dialysis treatment because of the low prevalence of adverse effects associated with their use. Although these antioxidant therapies seem promising, their use is controversial. Most studies demonstrating a benefit are either in vivo, isolated, or non-holistic studies. Large-scale randomized controlled trials (RCTs) are lacking for most of these compounds. Currently, there are ongoing trials for various antioxidants including resveratrol, NAC, coenzyme Q10, tocopherols, and curcumin. Table 1 describes various therapies that have shown promise and/or are under investigation [61-64,6770,88-100].

\section{Conclusion}

There is an abundance of crosstalk between pathways of inflammation and oxidative stress. Both inflammation and 
Table 1. Potential antioxidant therapeutics in CKD

\begin{tabular}{|c|c|c|c|}
\hline Therapy & Rationale for use & Role in CKD & References \\
\hline NAC & $\begin{array}{l}\text { Essential precursor for reduced glutathione, which } \\
\text { further detoxifies reactive species by enzymatic or } \\
\text { nonenzymatic reactions }\end{array}$ & $\begin{array}{l}\text { Reduces the levels of serum oxidative stress } \\
\text { biomarkers such as MDA and anti-MDA }\end{array}$ & [88] \\
\hline Vitamin C & $\begin{array}{l}\text { Superoxide anion and hydroxyl radical scavenger, } \\
\text { vitamin E regeneration }\end{array}$ & $\begin{array}{l}\text { Inhibits lipid peroxidation and reduces endothelial } \\
\text { dysfunction }\end{array}$ & {$[69,70]$} \\
\hline Vitamin E & $\begin{array}{l}\text { A lipid-soluble antioxidant that scavenges peroxyl } \\
\text { radical }\end{array}$ & $\begin{array}{l}\text { Increases level of serum NO and activities of } \\
\text { erythrocytic SOD and catalase, decreases serum } \\
\text { MDA }\end{array}$ & [68] \\
\hline Vitamin B & Inhibits formation of AGEs & Decreases disease progression and albuminuria & [89] \\
\hline Vitamin D & $\begin{array}{l}\text { Causes hypercalcemia and hyperphosphatemia in } \\
\text { CKD }\end{array}$ & Slows progression to ESRD & {$[90]$} \\
\hline Allopurinol & Xanthine oxidase inhibitor & $\begin{array}{l}\text { Decreases uric acid level and cardiovascular risk and } \\
\text { slows progression of renal disease }\end{array}$ & [91] \\
\hline GKT137831 & Dual inhibitor of Nox1 and Nox4 & $\begin{array}{l}\text { Attenuates glomerular structural changes, podocyte } \\
\text { loss, ECM accumulation, and albuminuria }\end{array}$ & {$[61,62]$} \\
\hline APX-115 & Pan-Nox inhibitor & $\begin{array}{l}\text { Decreases oxidative stress and albuminuria } \\
\text { and preserves creatinine level. Also inhibits } \\
\text { mitochondrial and peroxisomal dysfunction }\end{array}$ & {$[63,64]$} \\
\hline BARD & Activator of Nrf2 & $\begin{array}{l}\text { Increases estimated glomerular filtration rate and } \\
\text { preserves kidney function }\end{array}$ & [67] \\
\hline L-arginine & Precursor to NO and maintains endothelial function & Plays a protective role in ischemic acute renal failure & [92] \\
\hline L-carnitine & $\begin{array}{l}\text { Transporter of long-chain fatty acid chains across } \\
\text { the mitochondrial inner membrane, protects } \\
\text { membrane structures }\end{array}$ & $\begin{array}{l}\text { Increases glutathione level and glutathione } \\
\text { peroxidase activity and decreases MDA level }\end{array}$ & {$[93,94]$} \\
\hline Coenzyme Q10 & $\begin{array}{l}\text { Highly lipophilic molecule localized in mitochondria } \\
\text { that prevents membrane lipid peroxidation }\end{array}$ & $\begin{array}{l}\text { Improves mitochondrial function and decreases } \\
\text { oxidative stress }\end{array}$ & {$[95,96]$} \\
\hline Omega-3 PUFA & $\begin{array}{l}\text { Include DHA and EPA and possess anti-inflammatory } \\
\text { properties }\end{array}$ & $\begin{array}{l}\text { Reduces the inflammatory markers IL- } 6 \text {, IL-1 } 1 \beta \text {, TNF-a, } \\
\text { and CRP }\end{array}$ & [97] \\
\hline Curcumin & $\begin{array}{l}\text { Used as antioxidant, anti-inflammatory, antibacterial, } \\
\text { and antimicrobial reagent }\end{array}$ & Attenuates proteinuria, TGF- $\beta$, and IL- 8 & {$[98,99]$} \\
\hline Resveratrol & $\begin{array}{l}\text { Directly scavenges ROS and modulates the } \\
\text { expression and activity of antioxidant enzymes }\end{array}$ & Strong anti-inflammatory and antioxidant effects & [100] \\
\hline
\end{tabular}

AGE, advanced glycation end products; BARD, bardoxolone methyl; CKD, chronic kidney disease; CRP, C-reactive protein; DHA, docosahexanoic acid; ECM, extracellular matrix; EPA, eicosapentanoic acid; ESRD, end-stage renal disease; IL, interleukin; NAC, N-acetyl cysteine; NO, nitric oxide; Nox, nicotinamide adenine dinucleotide phosphate oxidase; Nrf2, nuclear factor erythroid 2-related factor 2; MDA, malondialdehyde; PUFA, polyunsaturated fatty acid; ROS, reactive oxygen species; SOD, superoxide dismutase; TGF- , transforming growth factor- $₫$; TNF, tumor necrosis factor.

oxidative stress have been implicated in various pathological systems that are prevalent in CKD, leading to progressive patient deterioration. Due to the complex nature of oxidative stress and the numerous molecular pathways involved, poly-pharmacotherapy with antioxidants might be effective in CKD patients. Many compounds have shown a beneficial role in reducing oxidative stress due to their free radical scavenging properties, indirect antioxidant properties, or anti- inflammatory actions. However, the most significant limitations of most of the relevant studies are small sample size and short-term follow-up. Hence, none of these molecules are routinely used in clinical practice. Thus, well-organized RCTs and comparative studies with long-term follow-up are warranted.

\section{Conflicts of interest}

All authors have no conflicts of interest to declare.

\section{Acknowledgments}

The authors thank Ms. Bandana Sahu for assistance in editing the manuscript.

\section{Authors' contributions}

Conceptualization: VT, VB

Investigation: SV, PS, SK

Writing-original draft: SV, PS, SK, VT, VB 
Writing-review \& editing: All authors

All authors read and approved the final manuscript.

\section{ORCID}

Sagar Verma, https://orcid.org/0000-0002-1568-5298

Priyanka Singh, https://orcid.org/0000-0003-4420-0664

Shiffali Khurana, https://orcid.org/0000-0001-7814-1311

Nirmal Kumar Ganguly, https://orcid.org/0000-0003-2233-9673

Ritushree Kukreti, https://orcid.org/0000-0002-6968-1129

Luciano Saso, https://orcid.org/0000-0003-4530-8706

Devinder Singh Rana, https://orcid.org/0000-0001-6622-6975

Vibha Taneja, https://orcid.org/0000-0001-5457-9992

Vinant Bhargava, https://orcid.org/0000-0002-3360-4666

\section{References}

1. Jha JC, Banal C, Chow BS, Cooper ME, Jandeleit-Dahm K. Diabetes and kidney disease: role of oxidative stress. Antioxid Redox Signal 2016;25:657-684.

2. Birben E, Sahiner UM, Sackesen C, Erzurum S, Kalayci O. Oxidative stress and antioxidant defense. World Allergy Organ J 2012;5:9-19.

3. Sayre LM, Smith MA, Perry G. Chemistry and biochemistry of oxidative stress in neurodegenerative disease. Curr Med Chem 2001;8:721-738.

4. Dhalla NS, Temsah RM, Netticadan T. Role of oxidative stress in cardiovascular diseases. J Hypertens 2000;18:655-673.

5. Giacco F, Brownlee M. Oxidative stress and diabetic complications. Circ Res 2010;107:1058-1070.

6. Andreadis AA, Hazen SL, Comhair SA, Erzurum SC. Oxidative and nitrosative events in asthma. Free Radic Biol Med 2003;35:213-225.

7. Kao MP, Ang DS, Pall A, Struthers AD. Oxidative stress in renal dysfunction: mechanisms, clinical sequelae and therapeutic options. J Hum Hypertens 2010;24:1-8.

8. Gupta A, Sharma S, Nain CK, Sharma BK, Ganguly NK. Reactive oxygen species-mediated tissue injury in experimental ascending pyelonephritis. Kidney Int 1996;49:26-33.

9. Gupta R, Verma I, Sharma S, Ganguly NK. Prevention of tissue injury in an ascending mouse model of chronic pyelonephritis: role of free radical scavengers. Comp Immunol Microbiol Infect Dis 2004;27:225-234.

10. Locatelli F, Canaud B, Eckardt KU, Stenvinkel P, Wanner C, Zoccali C. Oxidative stress in end-stage renal disease: an emerging threat to patient outcome. Nephrol Dial Transplant
2003;18:1272-1280.

11. Tucker PS, Dalbo VJ, Han T, Kingsley MI. Clinical and research markers of oxidative stress in chronic kidney disease. Biomarkers 2013;18:103-115.

12. Duni A, Liakopoulos V, Roumeliotis S, Peschos D, Dounousi E. Oxidative stress in the pathogenesis and evolution of chronic kidney disease: untangling Ariadne's thread. Int J Mol Sci 2019; 20:3711.

13. Dounousi E, Papavasiliou E, Makedou A, et al. Oxidative stress is progressively enhanced with advancing stages of CKD. Am J Kidney Dis 2006;48:752-760.

14. Hamer RA, El Nahas AM. The burden of chronic kidney disease. BMJ 2006;332:563-564.

15. Chapter 1: Definition and classification of CKD. Kidney Int Suppl (2011) 2013;3:19-62.

16. Tanner RM, Brown TM, Muntner P. Epidemiology of obesity, the metabolic syndrome, and chronic kidney disease. Curr Hypertens Rep 2012;14:152-159.

17. Granata S, Zaza G, Simone S, et al. Mitochondrial dysregulation and oxidative stress in patients with chronic kidney disease. BMC Genomics 2009;10:388.

18. Choi BH, Kang KS, Kwak MK. Effect of redox modulating NRF2 activators on chronic kidney disease. Molecules 2014;19:1272712759.

19. Holterman CE, Read NC, Kennedy CR. Nox and renal disease. Clin Sci (Lond) 2015;128:465-481.

20. Gorin Y, Block K. Nox4 and diabetic nephropathy: with a friend like this, who needs enemies? Free Radic Biol Med 2013;61:130142.

21. Fortuño A, Beloqui O, San José G, Moreno MU, Zalba G, Díez J. Increased phagocytic nicotinamide adenine dinucleotide phosphate oxidase-dependent superoxide production in patients with early chronic kidney disease. Kidney Int Suppl 2005;61(99):S71-S75.

22. DuPont JJ, Ramick MG, Farquhar WB, Townsend RR, Edwards DG. NADPH oxidase-derived reactive oxygen species contribute to impaired cutaneous microvascular function in chronic kidney disease. Am J Physiol Renal Physiol 2014;306:F1499-F1506.

23. Gondouin B, Jourde-Chiche N, Sallee M, et al. Plasma xanthine oxidase activity is predictive of cardiovascular disease in patients with chronic kidney disease, independently of uric acid levels. Nephron 2015;131:167-174.

24. Terawaki H, Murase T, Nakajima A, et al. The relationship between xanthine oxidoreductase and xanthine oxidase activities in plasma and kidney dysfunction. J Clin Exp Nephrol 2017;2:31. 
25. Wever R, Boer P, Hijmering M, et al. Nitric oxide production is reduced in patients with chronic renal failure. Arterioscler Thromb Vasc Biol 1999;19:1168-1172.

26. Baylis C. Nitric oxide deficiency in chronic kidney disease. Am J Physiol Renal Physiol 2008;294:F1-F9.

27. Schmidt RJ, Baylis C. Total nitric oxide production is low in patients with chronic renal disease. Kidney Int 2000;58:1261-1266.

28. Williams S, Malatesta K, Norris K. Vitamin D and chronic kidney disease. Ethn Dis 2009;19(4 Suppl 5):S5-8-11.

29. Noronha IL, Fujihara CK, Zatz R. The inflammatory component in progressive renal disease: are interventions possible? Nephrol Dial Transplant 2002;17:363-368.

30. Li N, Karin M. Is NF-kappaB the sensor of oxidative stress? FASEB J 1999;13:1137-1143.

31. Schreck R, Rieber P, Baeuerle PA. Reactive oxygen intermediates as apparently widely used messengers in the activation of the NF-kappa B transcription factor and HIV-1. EMBO J 1991;10:2247-2258.

32. Simmons EM, Langone A, Sezer MT, et al. Effect of renal transplantation on biomarkers of inflammation and oxidative stress in end-stage renal disease patients. Transplantation 2005;79:914-919.

33. Cachofeiro V, Goicochea M, de Vinuesa SG, Oubiña P, Lahera V, Luño J. Oxidative stress and inflammation, a link between chronic kidney disease and cardiovascular disease. Kidney Int Suppl 2008;(111):S4-S9.

34. Vaziri ND, Dicus M, Ho ND, Boroujerdi-Rad L, Sindhu RK. Oxidative stress and dysregulation of superoxide dismutase and NADPH oxidase in renal insufficiency. Kidney Int 2003;63:179185.

35. Suvakov S, Damjanovic T, Stefanovic A, et al. Glutathione S-transferase A1, M1, P1 and T1 null or low-activity genotypes are associated with enhanced oxidative damage among haemodialysis patients. Nephrol Dial Transplant 2013;28:202-212.

36. Karamouzis I, Sarafidis PA, Karamouzis M, et al. Increase in oxidative stress but not in antioxidant capacity with advancing stages of chronic kidney disease. Am J Nephrol 2008;28:397-404.

37. Yu M, Kim YJ, Kang DH. Indoxyl sulfate-induced endothelial dysfunction in patients with chronic kidney disease via an induction of oxidative stress. Clin J Am Soc Nephrol 2011;6:30-39.

38. Gouroju S, Rao PV, Bitla AR, Vinapamula KS, Manohar SM, Vishnubhotla S. Role of gut-derived uremic toxins on oxidative stress and inflammation in patients with chronic kidney disease. Indian J Nephrol 2017;27:359-364.

39. Liu WC, Tomino Y, Lu KC. Impacts of indoxyl sulfate and p-cresol sulfate on chronic kidney disease and mitigating effects of AST120. Toxins (Basel) 2018;10:367.

40. Gao H, Liu S. Role of uremic toxin indoxyl sulfate in the progression of cardiovascular disease. Life Sci 2017;185:23-29.

41. Fahal IH. Uraemic sarcopenia: aetiology and implications. Nephrol Dial Transplant 2014;29:1655-1665.

42. Liu WC, Wu CC, Lim PS, et al. Effect of uremic toxin-indoxyl sulfate on the skeletal system. Clin Chim Acta 2018;484:197-206.

43. Gryp T, Vanholder R, Vaneechoutte M, Glorieux G. p-Cresyl sulfate. Toxins (Basel) 2017;9:52.

44. Liakopoulos V, Roumeliotis S, Zarogiannis S, Eleftheriadis T, Mertens PR. Oxidative stress in hemodialysis: causative mechanisms, clinical implications, and possible therapeutic interventions. Semin Dial 2019;32:58-71.

45. Cristol JP, Canaud B, Rabesandratana H, Gaillard I, Serre A, Mion C. Enhancement of reactive oxygen species production and cell surface markers expression due to haemodialysis. Nephrol Dial Transplant 1994;9:389-394.

46. Ceballos-Picot I, Witko-Sarsat V, Merad-Boudia M, et al. Glutathione antioxidant system as a marker of oxidative stress in chronic renal failure. Free Radic Biol Med 1996;21:845-853.

47. Canaud B, Cristol J, Morena M, Leray-Moragues H, Bosc J, Vaussenat F. Imbalance of oxidants and antioxidants in haemodialysis patients. Blood Purif 1999;17:99-106.

48. Morena M, Delbosc S, Dupuy AM, Canaud B, Cristol JP. Overproduction of reactive oxygen species in end-stage renal disease patients: a potential component of hemodialysis-associated inflammation. Hemodial Int 2005;9:37-46.

49. Koenig JS, Fischer M, Bulant E, Tiran B, Elmadfa I, Druml W. Antioxidant status in patients on chronic hemodialysis therapy: impact of parenteral selenium supplementation. Wien Klin Wochenschr 1997;109:13-19.

50. Kalantar-Zadeh K, Brennan ML, Hazen SL. Serum myeloperoxidase and mortality in maintenance hemodialysis patients. Am J Kidney Dis 2006;48:59-68.

51. Maher ER, Wickens DG, Griffin JF, Kyle P, Curtis JR, Dormandy TL. Increased free-radical activity during haemodialysis? Nephrol Dial Transplant 1987;2:169-171.

52. Masakane I. Review: clinical usefulness of ultrapure dialysate. Recent evidence and perspectives. Ther Apher Dial 2006;10:348354.

53. Lonnemann G. Chronic inflammation in hemodialysis: the role of contaminated dialysate. Blood Purif 2000;18:214-223.

54. Jun M, Venkataraman V, Razavian M, et al. Antioxidants for chronic kidney disease. Cochrane Database Syst Rev 2012;10:CD008176. 
55. Siu YP, Leung KT, Tong MK, Kwan TH. Use of allopurinol in slowing the progression of renal disease through its ability to lower serum uric acid level. Am J Kidney Dis 2006;47:51-59.

56. Yelken B, Caliskan Y, Gorgulu N, et al. Reduction of uric acid levels with allopurinol treatment improves endothelial function in patients with chronic kidney disease. Clin Nephrol 2012;77:275282.

57. Filiopoulos V, Hadjiyannakos D, Vlassopoulos D. Febuxostat renoprotection in CKD patients with asymptomatic hyperuricemia. Am J Kidney Dis 2016;67:989-990.

58. Liao CY, Chung CH, Wu CC, et al. Protective effect of N-acetylcysteine on progression to end-stage renal disease: necessity for prospective clinical trial. Eur J Intern Med 2017;44:67-73.

59. Sahin G, Yalcin AU, Akcar N. Effect of N-acetylcysteine on endothelial dysfunction in dialysis patients. Blood Purif2007;25:309-315.

60. Gill PS, Wilcox CS. NADPH oxidases in the kidney. Antioxid Redox Signal 2006;8:1597-1607.

61. Jha JC, Gray SP, Barit D, et al. Genetic targeting or pharmacologic inhibition of NADPH oxidase nox4 provides renoprotection in long-term diabetic nephropathy. J Am Soc Nephrol 2014;25:12371254.

62. Gorin Y, Cavaglieri RC, Khazim K, et al. Targeting NADPH oxidase with a novel dual Nox1/Nox4 inhibitor attenuates renal pathology in type 1 diabetes. Am J Physiol Renal Physiol 2015;308:F1276-F1287.

63. Cha JJ, Min HS, Kim KT, et al. APX-115, a first-in-class pan-NADPH oxidase (Nox) inhibitor, protects $\mathrm{db} / \mathrm{db}$ mice from renal injury. Lab Invest 2017;97:419-431.

64. Kwon G, Uddin MJ, Lee G, et al. A novel pan-Nox inhibitor, APX115 , protects kidney injury in streptozotocin-induced diabetic mice: possible role of peroxisomal and mitochondrial biogenesis. Oncotarget 2017;8:74217-74232.

65. Ito M, Tanaka T, Nangaku M. Nuclear factor erythroid 2-related factor 2 as a treatment target of kidney diseases. Curr Opin Nephrol Hypertens 2020;29:128-135.

66. Nezu M, Suzuki N, Yamamoto M. Targeting the KEAP1-NRF2 system to prevent kidney disease progression. Am J Nephrol 2017;45:473-483.

67. Chin MP, Bakris GL, Block GA, et al. Bardoxolone methyl improves kidney function in patients with chronic kidney disease stage 4 and type 2 diabetes: post-hoc analyses from bardoxolone methyl evaluation in patients with chronic kidney disease and type 2 diabetes study. Am J Nephrol 2018;47:40-47.

68. Bhogade RB, Suryakar AN, Joshi NG, Patil RY. Effect of vitamin E supplementation on oxidative stress in hemodialysis patients.
Indian J Clin Biochem 2008;23:233-237.

69. Deicher R, Hörl WH. Vitamin C in chronic kidney disease and hemodialysis patients. Kidney Blood Press Res 2003;26:100-106.

70. Niki E. Interaction of ascorbate and alpha-tocopherol. Ann NY Acad Sci 1987;498:186-199.

71. Princen HM, van Duyvenvoorde W, Buytenhek R, et al. Supplementation with low doses of vitamin E protects LDL from lipid peroxidation in men and women. Arterioscler Thromb Vasc Biol 1995;15:325-333.

72. Wratten ML, Navino C, Tetta C, Verzetti G. Haemolipodialysis. Blood Purif 1999;17:127-133.

73. Boaz M, Smetana S, Weinstein T, et al. Secondary prevention with antioxidants of cardiovascular disease in endstage renal disease (SPACE): randomised placebo-controlled trial. Lancet 2000;356:1213-1218.

74. Boudouris G, Verginadis II, Simos YV, et al. Oxidative stress in patients treated with continuous ambulatory peritoneal dialysis (CAPD) and the significant role of vitamin C and E supplementation. Int Urol Nephrol 2013;45:1137-1144.

75. Kim MJ, Frankel AH, Donaldson M, et al. Oral cholecalciferol decreases albuminuria and urinary TGF- $\beta 1$ in patients with type 2 diabetic nephropathy on established renin-angiotensin-aldosterone system inhibition. Kidney Int 2011;80:851-860.

76. Aytaç MB, Deveci M, Bek K, Kayabey Ö, Ekinci Z. Effect of cholecalciferol on local arterial stiffness and endothelial dysfunction in children with chronic kidney disease. Pediatr Nephrol 2016;31:267-277.

77. Seibert E, Heine GH, Ulrich C, Seiler S, Köhler H, Girndt M. Influence of cholecalciferol supplementation in hemodialysis patients on monocyte subsets: a randomized, double-blind, placebo-controlled clinical trial. Nephron Clin Pract 2013;123:209-219.

78. Meireles MS, Kamimura MA, Dalboni MA, Giffoni de Carvalho JT, Aoike DT, Cuppari L. Effect of cholecalciferol on vitamin D-regulatory proteins in monocytes and on inflammatory markers in dialysis patients: a randomized controlled trial. Clin Nutr 2016;35:1251-1258.

79. Alvarez JA, Law J, Coakley KE, et al. High-dose cholecalciferol reduces parathyroid hormone in patients with early chronic kidney disease: a pilot, randomized, double-blind, placebo-controlled trial. Am J Clin Nutr 2012;96:672-679.

80. Sepidarkish M, Farsi F, Akbari-Fakhrabadi M, et al. The effect of vitamin D supplementation on oxidative stress parameters: a systematic review and meta-analysis of clinical trials. Pharmacol Res 2019;139:141-152.

81. Norris KC, Olabisi O, Barnett ME, et al. The role of vitamin D and oxidative stress in chronic kidney disease. Int J Environ Res Pub- 
lic Health 2018;15:2701.

82. Zhang F, Liu H, Liu D, et al. Effects of RAAS inhibitors in patients with kidney disease. Curr Hypertens Rep 2017;19:72.

83. Renke M, Lizakowski S, Tylicki L, et al. Aliskiren attenuates oxidative stress and improves tubular status in non-diabetic patients with chronic kidney disease: placebo controlled, randomized, cross-over study. Adv Med Sci 2014;59:256-260.

84. Jafar TH, Schmid CH, Landa M, et al. Angiotensin-converting enzyme inhibitors and progression of nondiabetic renal disease. A meta-analysis of patient-level data. Ann Intern Med 2001;135:73-87.

85. Kunz R, Friedrich C, Wolbers M, Mann JF. Meta-analysis: effect of monotherapy and combination therapy with inhibitors of the renin angiotensin system on proteinuria in renal disease. Ann Intern Med 2008;148:30-48.

86. Chung EY, Ruospo M, Natale P, et al. Aldosterone antagonists in addition to renin angiotensin system antagonists for preventing the progression of chronic kidney disease. Cochrane Database Syst Rev 2020;10:CD007004.

87. Hollenberg NK. Direct renin inhibition and the kidney. Nat Rev Nephrol 2010;6:49-55.

88. Giannikouris I. The effect of N-acetylcysteine on oxidative serum biomarkers of hemodialysis patients. Hippokratia 2015;19:131135.

89. Busch M, Göbert A, Franke S, et al. Vitamin B6 metabolism in chronic kidney disease: relation to transsulfuration, advanced glycation and cardiovascular disease. Nephron Clin Pract 2010;114:c38-c46.

90. Shoben AB, Rudser KD, de Boer IH, Young B, Kestenbaum B. Association of oral calcitriol with improved survival in nondialyzed CKD. J Am Soc Nephrol 2008;19:1613-1619.
91. Goicoechea M, de Vinuesa SG, Verdalles U, et al. Effect of allopurinol in chronic kidney disease progression and cardiovascular risk. Clin J Am Soc Nephrol 2010;5:1388-1393.

92. Schramm L, La M, Heidbreder E, et al. L-arginine deficiency and supplementation in experimental acute renal failure and in human kidney transplantation. Kidney Int 2002;61:1423-1432.

93. Fatouros IG, Douroudos I, Panagoutsos S, et al. Effects of L-carnitine on oxidative stress responses in patients with renal disease. Med Sci Sports Exerc 2010;42:1809-1818.

94. Matera M, Bellinghieri G, Costantino G, Santoro D, Calvani M, Savica V. History of L-carnitine: implications for renal disease. J Ren Nutr 2003;13:2-14.

95. Yeung CK, Billings FT 4th, Claessens AJ, et al. Coenzyme Q10 dose-escalation study in hemodialysis patients: safety, tolerability, and effect on oxidative stress. BMC Nephrol 2015;16:183.

96. Mehmetoglu I, Yerlikaya FH, Kurban S, Erdem SS, Tonbul Z. Oxidative stress markers in hemodialysis and peritoneal dialysis patients, including coenzyme Q10 and ischemia-modified albumin. Int J Artif Organs 2012;35:226-232.

97. Mas E, Barden A, Burke V, et al. A randomized controlled trial of the effects of n-3 fatty acids on resolvins in chronic kidney disease. Clin Nutr 2016;35:331-336.

98. Khajehdehi P, Pakfetrat M, Javidnia K, et al. Oral supplementation of turmeric attenuates proteinuria, transforming growth factor- $\beta$ and interleukin-8 levels in patients with overt type 2 diabetic nephropathy: a randomized, double-blind and placebo-controlled study. Scand J Urol Nephrol 2011;45:365-370.

99. Mori TA, Beilin LJ. Omega-3 fatty acids and inflammation. Curr Atheroscler Rep 2004;6:461-467.

100. Saldanha JF, Leal Vde O, Stenvinkel P, Carraro-Eduardo JC, Mafra D. Resveratrol: why is it a promising therapy for chronic kidney disease patients? Oxid Med Cell Longev 2013;2013:963217. 